\title{
Influence of Clinical Operative Technique on Debris Extrusion of Two Reciprocating Files
}

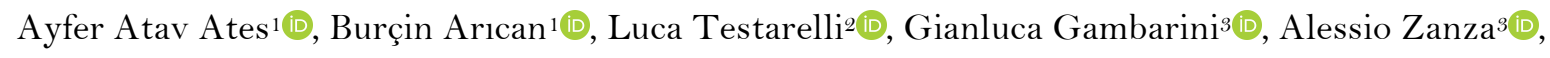 \\ Marco Seracchianis (1)
}

\footnotetext{
${ }^{1}$ Department of Endodontics, Istanbul Okan University, Faculty of Dentistry, Istanbul, Turkey.

${ }^{2}$ Department of Oral and Maxillofacial Sciences, University of Rome, Rome, Italy.

${ }^{3}$ Department of Oral and Maxillofacial Sciences, Sapienza University of Rome, Rome, Italy.
}

Correspondence: Luca Testarelli, Via Caserta 6,00161, Rome, Italy. E-mail: luca.testarelli@uniroma1.it

Academic Editor: Alidianne Fábia Cabral Cavalcanti

Received: 15 October 2020 / Review: 19 January 2021 / Accepted: 16 March 2021

How to cite: Ates AA, Arıcan B, Testarelli L, Gambarini G, Zanza A, Seracchiani M. Influence of clinical operative technique on debris extrusion of two reciprocating files. Pesqui Bras Odontopediatria Clín Integr. 2021; $21: e 0224$. https://doi.org/10.1590/pboci.2021.114

\begin{abstract}
Objective: To compare the influence of different clinical operative motions (pecking motion vs. MIMERACI) on apical debris extrusion using WaveOne Gold and EdgeOne Fire reciprocating files in the mesiobuccal canal of extracted molars. Material and Methods: Sixty mandibular molar teeth with curvature less than $20^{\circ}$ were divided into 4 groups ( $\mathrm{n}=15$ each): G1A: WOG pecking Group; G1B: WOG MIMERACI Group; G2A: EOF pecking Group; and G2B: EOF MIMERACI Group. The produced debris was collected in the preweighed Eppendorf tubes and following the shaping procedures; they dried in the incubator for 5 days at $70^{\circ} \mathrm{C}$. The tubes were weighed again, and the final extruded debris was measured by subtracting the pre-instrumentation from post-instrumentation weight of tubes. The canal preparation time was calculated with a digital chronometer. The obtained data were analyzed using two-way ANOVA at a 0.05 level of significance. Results: MIMERACI method significantly decreased the amount of debris pushed out in both instruments $(\mathrm{p}<0.05)$. Neither instruments nor clinical motions created a statistical difference regarding the required time ( $>0.05)$. Conclusion: All tested instruments pushed debris out apically at some level, but MIMERACI operative technique was associated with significantly less apical debris extrusion.
\end{abstract}

Keywords: Endodontics; Root Canal Therapy; Root Canal Preparation. 


\section{Introduction}

During root canal therapies, root canal filling material, irrigation solutions, bacteria, necrotic tissue remnants, dentin particles can apically extrude regardless of the instrumentation technique and rotary instruments used [1,2]. These extruded materials may trigger periapical inflammation, which may cause flareups, may increase post-operative pain and swelling, may negatively affect outcome [3,4].

Although every rotary or manual endodontic instrument can cause apical debris extrusion somehow, it was shown that cross-section design, kinematics, taper, tip size of the instruments affect the amount of it [5,6]. Reciprocation motion could increase the risk of pushing debris inside canals/beyond the apex since it consists of two different angles (rotating clockwise and counterclockwise), and flutes are designed to remove debris coronally only in one direction.

WaveOne Gold (WOG - Dentsply Maillefer, Ballaigues Switzerland) [7] and EdgeOne Fire (EOF EdgeEndo, Albuquerque, NM, USA) [8] have the same tip size and taper and are recommended to use with similar motion (angles and resulting speed) by their manufacturers. Both are single file techniques, working in a reverse reciprocating motion: $30^{\circ}$ clockwise and $150^{\circ}$ counterclockwise. The main difference between WOG and EOF is related to the manufacturing technology, with different, non-disclosed thermal treatments: Gold vs. FireWire heat treatment [9].

Many studies stated that reciprocation could play a critical role in increasing the risk of apical extrusion of debris, but no published studies evaluated if clinical motion could reduce this risk. For this reason, in the present study, a clinical motion, the so-called "MIMERACI", proposed by Gambarini et al. [10], has been tested to evaluate debris extrusion. The motion works for both continuous rotation and reciprocation since the resulting motion of NiTi reciprocation is a non-continuous rotation. MIMERACI is an acronym, which means manual insertion (MI), minimal engagement (ME), remove (R), and clean flutes (AC), irrigation (I). It is a very controlled clinical motion with $1 \mathrm{~mm}$ step advancements in the root canal. Authors claimed that the system could cause less debris production and extrusion by minimizing files' engagement, more frequent cleaning of flutes, and increasing the fresh irrigating solution.

While there are many studies [11-13] comparing debris extrusion of conventional hand instruments with rotary files, reciprocation and rotation motions with the same or different NiTi rotary files, there is no study that evaluates the influence of clinical operative motions on debris extrusion. Moreover, WOG and EOF have not been compared to date regarding the amount of debris extrusion in any study. Therefore, this study aimed to compare the amount of apically extruded debris produced by two reciprocating NiTi instruments used with a traditional pecking motion and the MIMERACI technique. The null hypothesis was that MIMERACI technique would not affect the amount of debris extrusion compared to a traditional pecking motion independently from the used reciprocating instrument.

\section{Material and Methods}

Selecting Samples

Freshly extracted one hundred fifty human mandibular first molar teeth were collected. The teeth used in the present study were extracted for periodontal mobility of Class 3 on Miller Classification [14], or orthodontic reasons. The teeth were stored inside a jar full of $2.6 \%$ sodium hypochlorite $(\mathrm{NaOCl})$ for $2 \mathrm{~h}$ then carried to a jar with $10 \%$ buffered formalin phosphate until usage. Digital radiographs were taken in two different directions. The curvature of the mesial root was calculated with Schneider's method [15] by using AutoCAD Software (Autodesk Inc., San Rafael, CA, USA). Only those have a degree of curvature less than $20^{\circ}$ 
and length more than $15 \mathrm{~mm}$ of mesial roots with two separate canals were used in this study. The teeth with open apex, resorption, or calcification and had root canal treatment before were omitted. The mesial roots of sixty teeth that met these criteria were separated with a high-speed diamond bur and then the coronal part was removed to get a $14 \mathrm{~mm}$ root length. The teeth surfaces were cleaned from soft and hard tissue remnants. A size \#10 K-file was inserted into the mesiobuccal canals to check canal openings and measure the working length (WL) by subtracting $1 \mathrm{~mm}$ from the length that tip of the instrument seen in the major foramen. When \#10 K-file loose at WL, this sample was discarded. An operating microscope (Moller Spectra 500, MollerWedel GmbH, Wedel, Germany) was used during these procedures. The samples were randomly divided into two groups with two subgroups (www.randomizer.org) (n=15 each) and numbers were given to each.

\section{Experimental Design}

Sixty Eppendorf tubes were weighed without cover, and this was done three times by an electronic balance (Sartorius AG, Göttingen, Germany) having an accuracy of $0.00001 \mathrm{~g}$. The average values were recorded for each one. A study design by Myers and Montgomery [16] was used for the measurement of debris extrusion with some modifications (Figure 1). Each tooth was inserted into the hole, which was prepared on the cover and supported with cyanoacrylate to stabilize it. A $27 \mathrm{G}$ needle was used to balance the air pressure of the inside and outside environment. The prepared covers with root and needle fitted to the Eppendorf tubes. The Eppendorf tubes were placed inside the glass vials filled with water at a controlled temperature of $37^{\circ} \mathrm{C}$, as confirmed with an electrode thermometer - MN35 Digital Mini Multimeter (Extech Instruments, Waltham, MA, USA). The glass container was coated with aluminum foil to avoid bias.

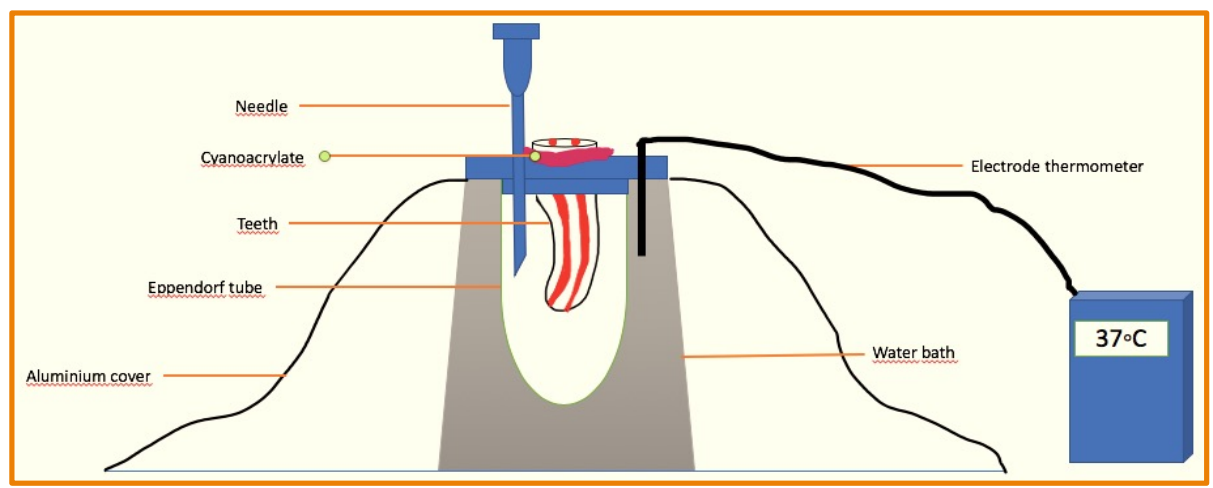

Figure 1. Schematic representation of the testing device.

Shaping Procedures

The two reciprocating files were operated with the same WaveOne All - and with the same endodontic VDW Gold (VDW, Munich, Germany). The files were used with different clinical motions.

- Group 1A: WOG / Traditional pecking method - The shaping procedures were performed applying only gentle inward pressure to the file. The instrument was used with a 2-3 mm amplitude with slow, in-and-out pecking motion (one peck) until WL was reached. The debris on the instrument was cleaned with sterile gauze after every 3 pecks.

- Group 1B: WOG / MIMERACI - The WOG files were operated with a clinical motion called MIMERACI described by Gambarini et al. [10] in a previous study. In this method, after each $1 \mathrm{~mm}$ progression in the canal, the file was removed, cleaned with sterile gauze, the root canal was irrigated and the file was reinserted into the canal. This procedure was repeated until WL was reached by WOG\# 25 file. 
- Group 2A: EOF / Traditional pecking method - EOF Primary file (\#25.06) was used with in-and-out motion advancing the file $2-3 \mathrm{~mm}$ with each stroke until reaching the WL. The instrument was cleaned each time, as explained in Group 1A.

- Group 2B: EOF / MIMERACI - EOF files were used with Waveone All program and all shaping procedures were performed as described in Group 1B.

In all groups, apical patency was checked with \#10 K-file to avoid apical blockage with debris. Single experienced endodontics who calibrated to the MIMERACI technique was performed all shaping procedures. A total of $12 \mathrm{~mL}$ bidistilled water was used for irrigation. Each file was used for 3 canals and then discarded. Irrigation was performed using a syringe and a side-vented $30 \mathrm{G}$ needle (NaviTip - Ultradent Products, Inc., South Jordan, UT, USA) in a back-and-forth motion and positioned $3 \mathrm{~mm}$ short of the WL. The required time was calculated with a digital chronometer during shaping and irrigation procedures.

After finishing root canal preparations, the cover with drainage syringe and root was removed. The debris around the root apex was cleaned with $1 \mathrm{ml}$ bidistilled water inside the Eppendorf tube. To evaporate the bidistilled water, the collection combination inside the tubes was dried at a temperature of $70^{\circ} \mathrm{C}$ for 5 days [17]. The Eppendorf tubes were weighted three times with the abovementioned electronic balance and then average weight recorded. Then, for each sample, the tare was subtracted from the final measurements to get the values. All measurements were done by a second examiner who was blinded to group contents.

\section{Data Analysis}

The data obtained were analyzed with two-way ANOVA at 0.05 level of significance using Minitab Statistical Software, version 18 (Minitab, LLC, State College, PA, USA).

\section{Results}

No instrument fracture occurred during instrumentation. The mean weight and standard deviation of the amount of apically extruded debris for each group were shown in Table 1. There was statistically no significant difference between WOG and EOF when used according to the manufacturer instructions (pecking) or MIMERACI technique ( $\mathrm{p}>0.05$ ). When two clinical motions were compared, MIMERACI method significantly decreased the quantity of debris extruded for both instruments $(\mathrm{p}<0.05)$. No correlation was found among the required time and the other variables ( $>>0.05)$ (Table 2$)$.

Table 1. The mean and standard deviations of the amount (gr) of extruded debris according to both instruments and instrumentation methods.

\begin{tabular}{cccccc}
\hline \multicolumn{1}{c}{ Groups } & \multicolumn{2}{c}{ A (Traditional Pecking) } & \multicolumn{2}{c}{ B (MIMERACI) } & p-value \\
& Mean & SD & Mean & SD & \\
\hline Group 1 (WOG) & 0.000853 & 0.000471 & 0.000324 & 0.000364 & 0.734 \\
Group 2 (EOF) & 0.000842 & 0.000687 & 0.000252 & 0.000246 & \\
p-value & & & 0.000 & & \\
\hline
\end{tabular}

Table 2. The mean and standard deviations of the operating time (seconds).

\begin{tabular}{|c|c|c|c|c|c|}
\hline \multirow[t]{2}{*}{ Groups } & \multicolumn{2}{|c|}{ A (Traditional Pecking) } & \multicolumn{2}{|c|}{ B (MIMERACI) } & \multirow[t]{2}{*}{ p-value } \\
\hline & Mean & SD & Mean & $\mathrm{SD}$ & \\
\hline Group 1 (WOG) & 126.87 & 10.44 & 128.07 & 9.07 & 0.727 \\
\hline Group 2 (EOF) & 127.93 & 8.46 & 128.67 & 8.97 & \\
\hline p-value & & & & & \\
\hline
\end{tabular}




\section{Discussion}

The standardization of experimental design and teeth are required factors to have valid results in apical debris extrusion studies. Unlike other studies $[2,18,19]$ in which single-rooted teeth were used, mandibular molar teeth with mature apices were chosen in the present study. Besides, anatomical differences such as curvature degrees and working lengths of teeth were also standardized. Due to the standardization of apical foramen diameter is indispensable for the extrusion studies [20], we discarded the samples when \#10 Kfile pass through easily from the apex during the WL determination. Because the amount of extruded debris was extremely low, the tubes were weighed three times using microbalance with an accuracy of 10-5. Moreover, the previously tested debris collection method, which is reliable, easy, cheap, and repeatable, was imitated in this study with some modifications. To mimic in vivo conditions, all the root canal shaping procedure of the mesiobuccal canal was performed at body temperature.

There are numerous publications that evaluate the clinical relevance [21,22] of debris extrusion and compare the debris extrusion caused by various instruments and motors motions [2,17,19]. To the authors' knowledge, this is the first study evaluating differences between WOG and EOF regarding apical debris extrusion. Although WOG and EOF have similar designs regarding the same tip size, taper, and cross-section, they have different heat processes and alloy, which may affect their clinical performance mainly in curved canals. EOF Fire-Wire heat treatment was shown to improve flexibility and fatigue when compared to WOG [9]. However, in the present study, no statistically significant difference was observed between the two tested instruments on the amount of extruded debris, both using traditional pecking motion and MIMERACI. A possible explanation is that severe canal curvatures were not included in the study since the main goal was to evaluate the influence of the instrumentation technique, minimizing factors related to anatomy.

To date, no file system was found to prevent totally the debris transportation to the apical area and their extrusion. According to Caviedes-Bucheli et al. [23], the instrument's design has an influence on apical debris extrusion. In the present study, two similar designs were selected to minimize its possible impact on debris: WOG and EOF have similar parallelogram cross-sections and the same dimensions (tip size and tapers). Both systems caused very low and similar debris extrusion.

Many researches have shown the quantity of debris extrusion by different files [18,19,24], but no study was focused on different clinical operative motions. In the present study, WOG and EOF were used according to manufacturers' instructions (pecking motion) and with MIMERACI technique. Results showed that the latter method produced significantly less debris extrusion with both instruments. Therefore, the null hypothesis was rejected.

Gambarini et al. [10], who proposed MIMERACI clinical motion in 2017, reported that this technique has three main advantages: the manual insertion and the minimal $(1 \mathrm{~mm})$ progression towards the apex allow a controlled engagement and controlled production of debris, avoiding overfilling of flutes; this progression in steps should be repeated a few times until reaching the working length; after each step (a small progression into the canal just $1 \mathrm{~mm}$ deeper than manual insertion), the instruments should be removed and flutes cleaned outside the canal, minimizing the risk of pushing debris inside or being push out apically; Irrigation after each step improves cleaning, debris removal and reduce, together with the $1 \mathrm{~mm}$ progression, the risk of canal blockage from an excessive amount of debris.

Gambarini et al. [10], using Twisted File Adaptive instruments (SybronEndo, Orange, CA, USA) reciprocating instruments, showed that MIMERACI technique had better clinical results (reducing post- 
operative pain) when compared to traditional pecking motion. Considering the relation between debris extrusion and post-operative pain, the present study results could be a confirmation of those findings.

Recent studies [2,20] conducted with different instrumentation systems concluded that faster shaping procedures like single-file techniques could cause more debris transportation than sequenced file systems. Our results showed that if a single file is properly used with a more controlled technique (MIMERACI), significantly less debris can be produced without losing the advantage of a faster shaping procedure. No statistically significant difference in instrumentation time was found when the two different clinical operative motions were used, independently from the used instrument.

In clinical endodontics, $\mathrm{NaOCl}$ is a widely used irrigation solution for removing organic tissue. However, in the present study, to avoid the crystallization of sodium, which may cause debris mismeasurements due to remained sodium crystals after evaporation, bidistilled water was used [25,26]. The proximity of the irrigation needle to the apical construction increases the effectiveness of irrigation as well as the possibility of undesirable periapical over extrusions. Thus in all cases, the side-vented needle was placed 3 $\mathrm{mm}$ beyond the working length to deliver irrigant and prevent the possibility of irrigant extrusion caused by open-ended needle [27].

Despite all the aforementioned precautions, the authors are confronted with several limitations. The biggest problem was to mimic the in vivo conditions. In vitro studies, it is not possible to standardize the microhardness of dentin, which differs among the teeth that may affect the produced and extruded debris [28]. And also, the results should not be generalized to clinic conditions directly because of the lack of pulpal, periodontal tissues, and back-pressure of periapical tissues in this experimental design [29,30]. In addition, the ambient air and humidity may have an impact on the measurements of the extruded debris, which is quite low [31]. All these factors make it difficult to reflect the experimental study results to the clinic. Moreover, further in vivo and in vitro studies will be needed to better evaluate the influence on debris extrusion of the MIMERACI technique and stress generated during instrumentation to complete the evaluation on the technique $[32,33]$.

\section{Conclusion}

Within the limitation of this in vitro study, the influence of different clinical motion on apical debris extrusion was demonstrated. The MIMERACI technique caused significantly less debris extrusion, independently from the different tested reciprocating instruments, without negatively affecting instrumentation time.

\section{Authors' Contributions}

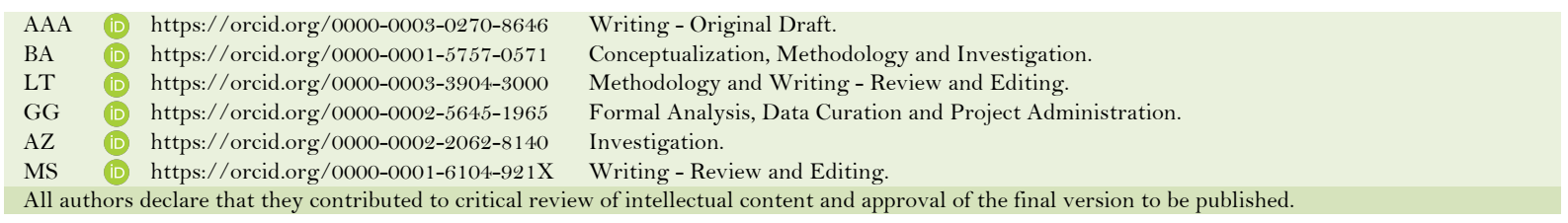

\section{Financial Support}

None.

\section{Conflict of Interest}

The authors declare no conflicts of interest. 


\section{Data Availability}

The data used to support the findings of this study can be made available upon request to the corresponding author.

\section{References}

[1] Betti L, Bramante C. Quantec SC rotary instruments versus hand files for gutta-percha removal in root canal retreatment. Int Endod Journal 2001; 34(7):514-9. https://doi.org/10.1046/j.1365-2591.2001.00424.x

[2] Bürklein S, Schäfer E. Apically extruded debris with reciprocating single-file and full-sequence rotary instrumentation systems. J Endod 2012; 38(6):850-2. https://doi.org/10.1016/j.joen.2012.02.017

[3] Ruiz-Hubard EE, Gutmann JL, Wagner MJ. A quantitative assessment of canal debris forced periapically during root canal instrumentation using two different techniques. J Endod 1987; 13(12):554-8.

https://doi.org/10.1016/Soo99-2399(87)80004-3

[4] Seltzer S, Naidorf IJ. Flare-ups in endodontics: I. Etiological factors. J Endod 1985; 11(11):472-8. https://doi.org/10.1016/Soo99-2399(85)80220-X

[5] Arslan H, Khalilov R, Doğanay E, Karatas E. The effect of various kinematics on postoperative pain after instrumentation: a prospective, randomized clinical study. J Appl Oral Sci 2016; 24(5):503-8. https://doi.org/10.1590/1678-775720160136

[6] Borges ÁH, Pereira TM, Porto AN, de Araújo Estrela CR, Miranda Pedro FL, et al. The influence of cervical preflaring on the amount of apically extruded debris after root canal preparation using different instrumentation systems. J Endod 2016; 42(3):465-9. https://doi.org/10.1016/j.joen.2015.10.010

[7] Dentsply. Wave One Gold Brochure. 2015. Available from: https://www.dentsplysirona.com/content/dam/dentsply/pim/en_GB/Endodontics/Obturation/Paper_Points/Wav eOne_Gold_Absorbent_Points/WaveOne\%20GOLD\%20Brochure\%202015.pdf. [Accessed on March 18, 2020].

[8] EdgeEndo, Edge One Fire Product Catalogue. 2019. Available from: https://www.edgeendo.com/wpcontent/uploads/2019/01/Product-Catalog-January-2019.pdf. [Accessed on July 27, 2020].

[9] Gambarini G, Galli M, Di Nardo D, Seracchiani M, Donfrancesco O, Testarelli L. Differences in cyclic fatigue lifespan between two different heat treated NiTi endodontic rotary instruments: WaveOne Gold vs EdgeOne Fire. J Clin Exp Dent 2019; 11(7):e609-e613. https://doi.org/10.4317/jced.55839

[10] Gambarini G, Di Nardo D, Miccoli G, Guerra F, Di Giorgio R, Di Giorgio G, et al. The Influence of a new clinical motion for endodontic instruments on the incidence of postoperative pain. Clin Ter 2017; 168(1):e23-e27. https://doi.org/10.7417/CT.2017.1977

[11] Alves FR, Paiva PL, Marceliano-Alves MF, Cabreira LJ, Lima KC, Siqueira JF Jr, et al. Bacteria and hard tissue debris extrusion and intracanal bacterial reduction promoted by XP-endo Shaper and Reciproc instruments. J Endod 2018; 44(7):1173-8. https://doi.org/10.1016/j.joen.2018.04.007

[12] Frota MMA, Bernardes RA, Vivan RR, Vivacqua-Gomes N, Duarte MAH, Vasconcelos BC. Debris extrusion and foraminal deformation produced by reciprocating instruments made of thermally treated NiTi wires. J Appl Oral Sci 2018; 26:e201702 15. https://doi.org/10.1590/1678-7757-2017-0215.

[13] Topçuoğlu G, Topçuoğlu HS, Akpek F. Evaluation of apically extruded debris during root canal preparation in primary molar teeth using three different rotary systems and hand files. Int J Paediatr Dent 2016; 26(5):357-63. https://doi.org/10.1111/ipd.12208

[14] Miller PD Jr. A classification of marginal tissue recession. Int J Perio Rest Dent 1985; 5(2):9-13.

[15] Schneider SW. A comparison of canal preparations in straight and curved root canals. Oral Surg Oral Med Oral Pathol Oral Radiol 1971; 32(2):271-5. https://doi.org/10.1016/0030-4220(71)90230-1

[16] Myers GL, Montgomery S. A comparison of weights of debris extruded apically by conventional filing and canal master techniques. J Endod 1991; 17(6):275-9. https://doi.org/10.1016/Soo99-2399(06)81866-2

[17] Koçak S, Koçak MM, Sağlam BC, Türker SA, Sağsen B, Er Ö. Apical extrusion of debris using self-adjusting file, reciprocating single-file, and 2 rotary instrumentation systems. J Endod 2013; 39(10):1278-80. https://doi.org/10.1016/j.joen.2013.06.013

[18] Bürklein S, Benten S, Schäfer E. Quantitative evaluation of apically extruded debris with different single-file systems: Reciproc, F360 and OneShape versus Mtwo. Int Endod J 2014; 47(5):405-9. https://doi.org/10.1111/iej.12161

[19] Topçuoğlu HS, Zan R, Akpek F, Topçuoğlu G, Ulusan Ö, Aktı A, et al. Apically extruded debris during root canal preparation using Vortex Blue, K3 XF, ProTaper Next and Reciproc instruments. Int Endod J 2016; 49(12):1183-7. https://doi.org/10.1111/iej.12572

[20] Boijink D, Costa DD, Hoppe CB, Kopper PMP, Grecca FS. Apically extruded debris in curved root canals using the WaveOne Gold reciprocating and Twisted File Adaptive systems. J Endod 2018; 44(8):1289-92. https://doi.org/10.1016/j.joen.2018.04.011

[21] Silva EJ, Sá L, Belladonna FG, Neves AA, Accorsi-Mendonça T, Vieira VT, et al. Reciprocating versus rotary systems for root filling removal: assessment of the apically extruded material. J Endod 2014; 40(12):2077-80. https://doi.org/10.1016/j.joen.2014.09.009 
[22] Caviedes-Bucheli J, Azuero-Holguin MM, Gutierrez-Sanchez L, Higuerey-Bermudez F, Pereira-Nava V, Lombana N, et al. The effect of three different rotary instrumentation systems on substance $\mathrm{P}$ and calcitonin gene-related peptide expression in human periodontal ligament. J Endod 2010; 36(12):1938-42. https://doi.org/10.1016/j.joen.2010.08.043

[23] Caviedes-Bucheli J, Castellanos F, Vasquez N, Ulate E, Munoz HR. The influence of two reciprocating single-file and two rotary-file systems on the apical extrusion of debris and its biological relationship with symptomatic apical periodontitis. A systematic review and meta-analysis. Int Endod J 2016; 49(3):255-70. https://doi.org/10.1111/iej.12452

[24] Koçak MM, Çiçek E, Koçak S, Sağlam BC, Yılmaz N. Apical extrusion of debris using ProTaper Universal and ProTaper Next rotary systems. Int Endod J 2015; 48(3):283-6. https://doi.org/10.1111/iej.12313

[25] Sen OG, Bilgin B, Koçak S, Sağlam BC, Koçak MM. Evaluation of Apically Extruded Debris Using Continuous Rotation, Reciprocation, or Adaptive Motion. Braz Dent J 2018; 29(3):245-248. https://doi.org/10.1590/0103-6440201801967

[26] Karataslioglu E, Arslan H, Er G, Avci E. Influence of canal curvature on the amount of apically extruded debris determined by using three-dimensional determination method. Aust Endod J 2019; 45(2):216-24. https://doi.org/10.1111/aej.12311

[27] Altundasar E, Nagas E, Uyanik O, Serper A. Debris and irrigant extrusion potential of 2 rotary systems and irrigation needles. Oral Surg Oral Med Oral Pathol Oral Radiol Endod 2011; 112(4):e31-e35. https://doi.org/10.1016/j.tripleo.2011.03.044

[28] Tanalp J, Güngör T. Apical extrusion of debris: a literature review of an inherent occurrence during root canal treatment. Int Endod J 2014; 47(3):211-21. https://doi.org/10.1111/iej.12137

[29] De-Deus GA, Nogueira Leal Silva EJ, Moreira EJ, de Almeida Neves A, Belladonna FG, Tameirão M. Assessment of apically extruded debris produced by the self-adjusting file system. J Endod 2014; 40(4):526-9. https://doi.org/10.1016/j.joen.2013.07.031

[30] Mohorn HW, Dowson J, Blankenship JR. Odontic periapical pressure following vital pulp extirpation. Oral Surg Oral Med Oral Pathol 1971; 31(4):536-44. https://doi.org/10.1016/0030-4220(71)90350-1

[31] Fairbourn DR, McWalter GM, Montgomery S. The effect of four preparation techniques on the amount of apically extruded debris. J Endod 1987; 13(3):102-8. https://doi.org/10.1016/Soo99-2399(87)80174-7

[32] Di Nardo D, Seracchiani M, Mazzoni A, Del Giudice A, Gambarini G, Testarelli L. Torque range, a new parameter to evaluate new and used instrument safety. Appl Sci 2020; 10(10):3418. https://doi.org/10.3390/app10103418

[33] Gambarini G, Miccoli G, D'Angelo M, Seracchiani M, Obino FV, Reda R, et al. The relevance of operative torque and torsional resistance of nickel-titanium rotary instruments: A preliminary clinical investigation. Saudi Endod J 2020; 10(3):260-4. https://doi.org/10.4103/sej.sej_157_19 